\title{
Miniaturized P-band Beamforming Synthetic Aperture Radar Transceiver
}

\author{
Martin L. Perrine, Rafael Rincon, \\ Steven Van Nostrand, Hanson Nguyen, \\ and Miguel A. Moe \\ NASA Goddard Space Flight Center, \\ Greenbelt, MD, USA
}

\author{
Hjalti H. Sigmarsson and Mark B.Yeary \\ Advance Radar Research Center \\ School of Electrical and Computer Engineering \\ University of Oklahoma \\ Norman, OK, USA
}

\begin{abstract}
The next generation synthetic aperture radar (SAR) instruments for the study of Earth and planets will employ multiple-input multiple output architectures and advanced beamforming techniques to significantly enhance the capabilities of remote sensing radars. One key component in realizing these instruments is a compact, lightweight and power efficient radar transceiver. To this end a $\mathrm{P}$-band radar transceiver was developed to advance the technical readiness level (TRL) level toward spaceborne SAR instruments at the NASA Goddard Space Flight Center (GSFC).
\end{abstract}

Keywords-SAR, transceiver, radar, SSPA

\section{INTRODUCTION}

Scientists and engineers at the NASA Goddard Space Flight Center have been developing concepts for spaceborne next generation digital beamforming synthetic aperture radar (SAR) instruments applicable to NASA Earth science and planetary missions.[1] These instruments employ multiple-input multiple-output (MIMO) radar transceiver, software defined waveforms, and advanced digital beamforming (DBF) techniques to achieve capabilities beyond the current state-ofthe-art in radar remote sensing [2]. The general mission concept of using a digital beamforming SAR for planetary science application is shown in Fig. 1.

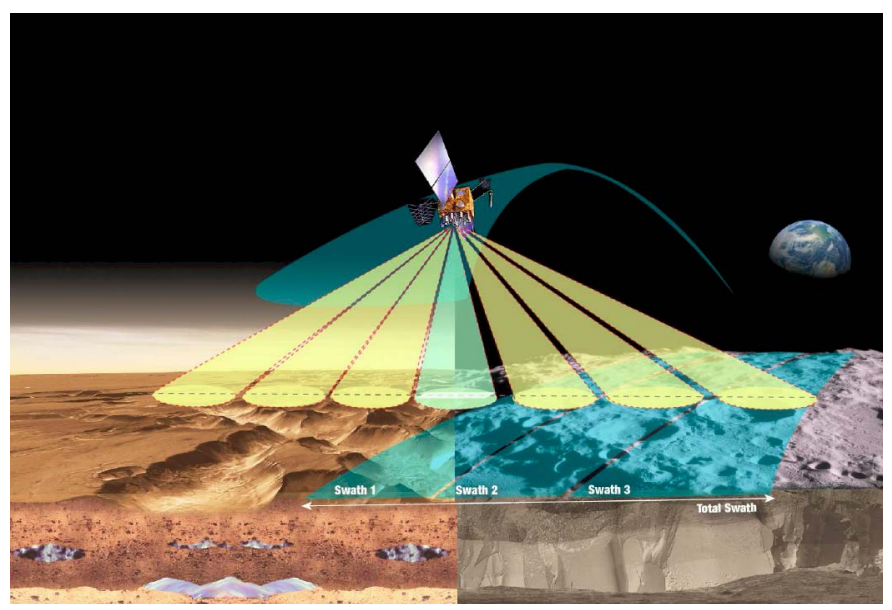

Fig. 1. Beam steerable SAR concept for planetary science application.
A study conducted By NASA GSFC, Instrument Design Lab (IDL) (May 2013) concluded that the development of a compact, lightweight and power efficient radar transceiver module was a critical and necessary step in the implementation of this type of spaceborne SAR instrument

For this reason, we have developed a prototype miniature Pband radar transceiver, directly applicable to two concepts for future spaceborne missions: The Carbon and Ecosystem Structure Agile SAR (CEASAR), and Space Exploration SAR (SESAR).[3]

\section{INSTRUMENT REQUIREMENTS}

The "path to space" concept for an Earth Science focus (Ecological System remote sensing) calls for a 250 channel Pband SAR with a $30 \mathrm{MHz}$ operational channel bandwidth. With such a large number of channels, an affordable, compact, reliable, low power and lightweight transceiver is absolutely required.

A planetary SAR mission does not have the strict spectral restrictions that an Earth science mission does and a system with up to $200 \mathrm{MHz}$ bandwidth is desired to increase measurement resolution.

To support both mission types a common transceiver module is desirable to save both cost and development time. A printed circuit board (PCB) approach was thought to be the best first step. The basic system design considerations and rationales adopted in the transceiver development are provided in Table I.

\section{DESIGN}

This prototype transceiver module was developed with heritage from two Goddard airborne instruments: Ecological Synthetic Aperture Radar (EcoSAR) [4]-[6] and Digital Beamforming Synthetic Aperture Radar (DBSAR) [7]-[9].

The design effort started with the basic architecture approach from EcoSAR with appropriate modifications. Both units operate directly at P-band $(435 \mathrm{MHz})$ without frequency conversion. Similar to EcoSAR, direct digital signal (DDS) sources and analog to digital (A/D) convertors are used for transmit waveform generation and echo signal recording respectively. The basic design for a single channel is shown in Fig. 2. 


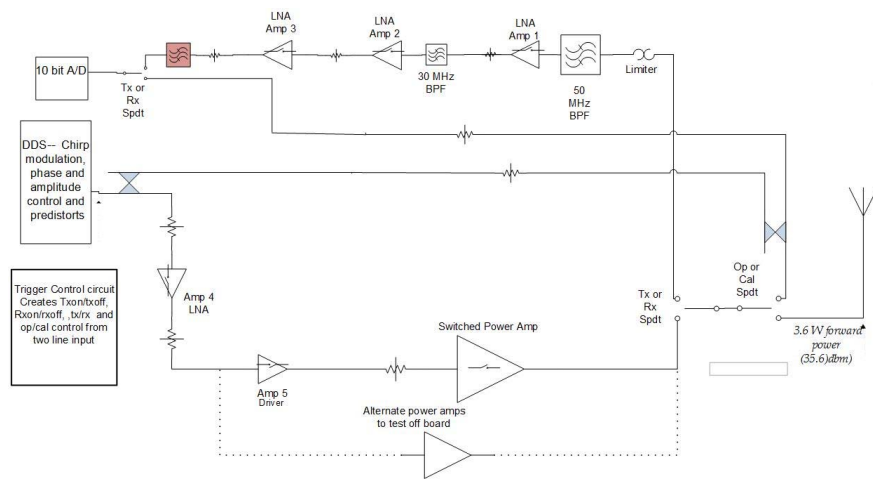

Fig. 2. Transceiver architecture.

TABLE I

\begin{tabular}{|c|c|}
\hline Calibration & $\begin{array}{l}\text { Conducted occasionally, every } 10 \\
\text { minutes or so; not on a pulse-by- } \\
\text { pulse basis. }\end{array}$ \\
\hline $\begin{array}{l}\text { Broadband } \\
\text { beam steering }\end{array}$ & $\begin{array}{l}\text { Need to vary phase by frequency to } \\
\text { steer tx beam for } 200 \mathrm{MHz} \text { mode. } \\
\text { Done by signal source. }\end{array}$ \\
\hline $\begin{array}{l}\text { Amp/phase } \\
\text { variation in } \\
\text { trans. over BW }\end{array}$ & $\begin{array}{l}\text { Assume significant phase/amplitude } \\
\text { variation over } 200 \mathrm{MHz} \mathrm{BW} \text {, } \\
\text { correction in both tx and rx will be } \\
\text { required. Corrections will be based } \\
\text { on measurements during the cal. } \\
\text { cycle. }\end{array}$ \\
\hline $\begin{array}{l}\text { Nonlinear tx } \\
\text { operation }\end{array}$ & $\begin{array}{l}\text { Predistortion required for nonlinear } \\
\text { operation. Performed by signal } \\
\text { source. }\end{array}$ \\
\hline $\begin{array}{l}\text { Radio } \\
\text { Frequency } \\
\text { Interference }\end{array}$ & $\begin{array}{l}\text { In band signals are filtered in the } \\
\text { digital receiver (rx). For Earth } \\
\text { science, filters protects against strong } \\
\text { out-of-band interferers on rx. }\end{array}$ \\
\hline $\begin{array}{l}\text { Transceiver } \\
\text { architecture }\end{array}$ & $\begin{array}{l}\text { No up/down convertors, nor analog } \\
\text { phase and amplitude control. } \\
\text { Independent cal. path for both tx and } \\
\text { rx path. }\end{array}$ \\
\hline Test modes & $\begin{array}{l}\text { Desire to test on the ground (drives } \\
\text { extra switches). }\end{array}$ \\
\hline $\begin{array}{l}\text { Non-calibrated } \\
\text { components } \\
\text { (cables) }\end{array}$ & $\begin{array}{l}\text { Amplitude and phase variation can } \\
\text { be accounted for by monitoring } \\
\text { temperature. }\end{array}$ \\
\hline BW & $\begin{array}{l}30 \mathrm{MHz} \text { for Earth science, } \\
\text { expandable to } 200 \mathrm{MHz} \text { for } \\
\text { planetary. }\end{array}$ \\
\hline Modulation & $\begin{array}{l}\text { Performed by direct digital signal } \\
\text { (DDS) sources. }\end{array}$ \\
\hline
\end{tabular}

EcoSAR's design took a hybrid approach. With minimal concern on size and power it utilized "connectorized" RF components for the high transmit (tx) power parts. The low power components were placed on a printed circuit board (PCB). The EcoSAR thermal tray populated with two of four channels installed is shown in Fig. 3. Each channel is approximately 10 " $\times 8$ " $\mathrm{x} 7$ " and weighs 7 pounds.

This effort combined all transceiver functions onto a single compact printed circuit board (PCB) with a highly efficient integrated power distribution. The result is a significant reduction in size, weight, and power, though RF transmit power is reduced $3 \mathrm{~dB}$. The board is 4 " $\times 5$ " $x 1$ " weighing 0.2 pounds

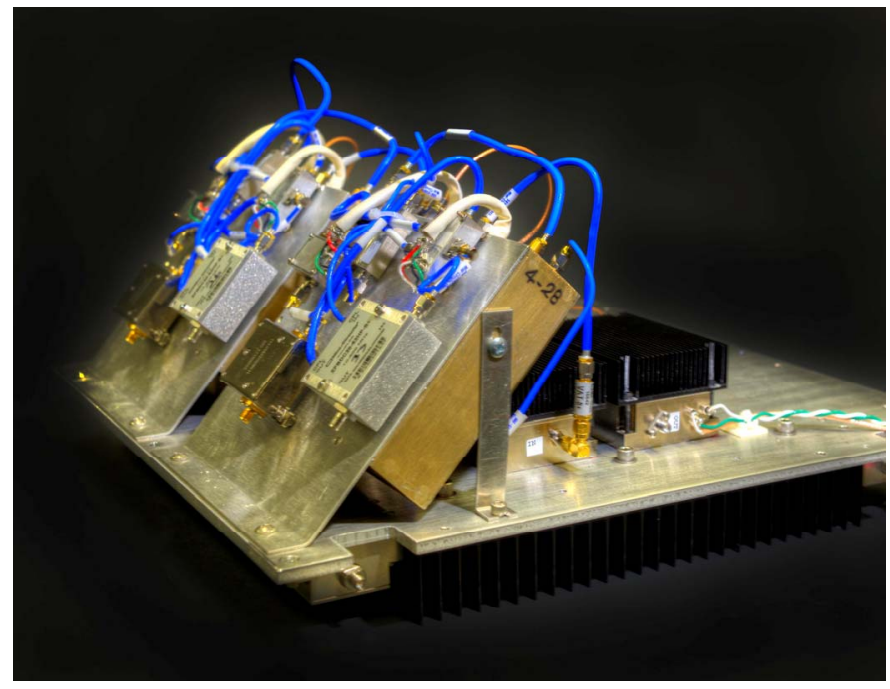

Fig. 3. EcoSAR airborne transceiver four channel tray with two channels mounted.

and will be installed in an electromagnetic interference (EMI) chassis with a heat sink.

High efficiency solid state power amplifiers (SSPA) and the transmit/receive $(\mathrm{T} / \mathrm{R})$ selector were the initial focus and drove other key design parameters. The SSPA was quickly identified as a critical item with limited off-the-shelf options. To support the study of other SSPAs in the future, provisions were made to bypass the onboard SSPA.

PSpice modeling was utilized for design validation of critical sections of the circuit.

RF circuit power efficiency was improved by using high speed muting for all amplifiers. Average power consumption for each amplifier is reduced by its operating duty cycle whether transmit or receive. This function also simplifies the isolation design to address transmitter leakage into the calibration and receive paths.

For this prototype development a commercial SSPA was found that had a one $\mathrm{dB}$ compression point $(\mathrm{P} 1 \mathrm{~dB})$ of 5 Watts and could support turn on/off time from 36us down to as low as $2 \mu$ s depending on tuning parameters. Fig. 4 shows the minimum SSPA turn on and off timing measurements at full power. This particular SSPA also was designed to be very efficient with a high power added efficiency of up to $50 \%$.

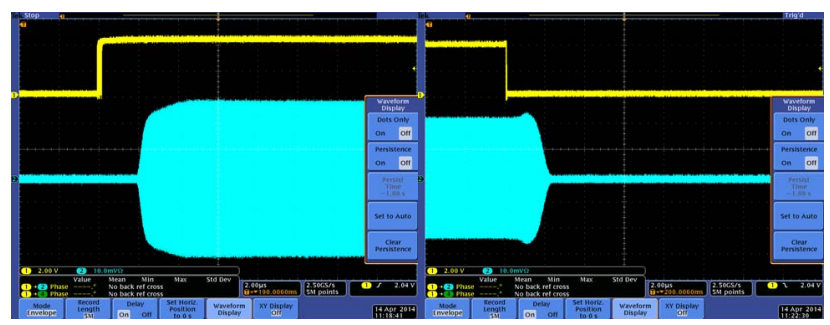

Fig. 4. Minimum turn on and off times for the SSPA at full power. 


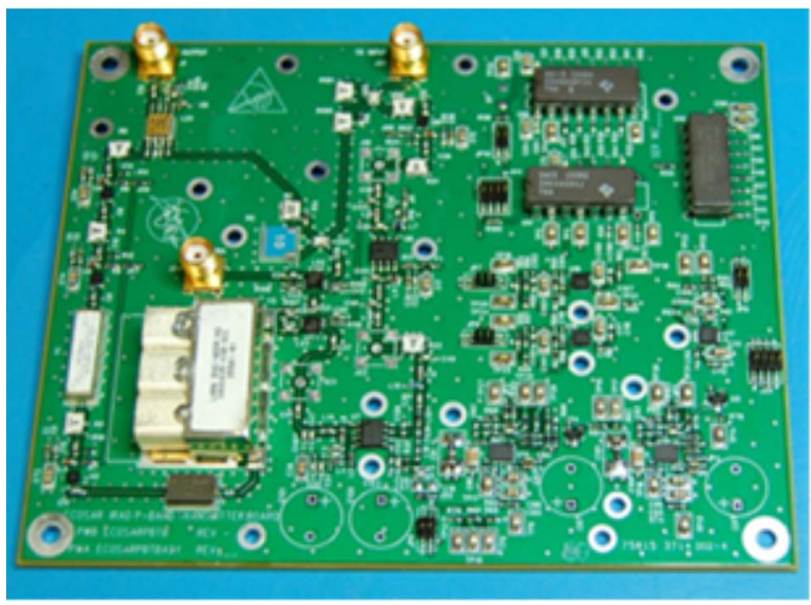

Fig. 5. Miniaturized P-band transceiver PCB.

A switching power distribution circuit, designed by the NASA GSFC Power Systems Branch was added to the board to further improve board efficiency and simplify power distribution for the spacecraft. A single $8 \mathrm{~V}$ source is used to feed the board. Two synchronous buck convertors are used for primary power. One feeds 7V to the SSPA while the other feeds three low dropout adjustable regulators that create $5 \mathrm{~V}$ for the digital components, and $5 \mathrm{~V}$ and $3.3 \mathrm{~V}$ for the analog components. Both types of regulators have at least $80 \%$ efficiency. The power dissipated in the distribution circuit is under $3 \mathrm{~W}$ compared to $19 \mathrm{~W}$ if conventional linear devices were used.

A solid state switch was chosen for the T/R selector rather than a circulator, due to size, weight, and isolation trade-offs.

All parts selected are commercially available and have a path to space flight qualification. The NASA GSFC Parts, Packaging and Assembly Technologies Branch confirmed all parts could be qualified or a qualified sister part is available. Parts were reused in the design where possible to reduce the number of space flight parts to qualify and manage. The parts selected also support the expansion to $200 \mathrm{MHz}$ bandwidth needed for planetary science. The SSPA circuit will require careful optimization, however.

Commercial evaluations boards were purchased where available for part selection and to reduce development time.

\section{BUILD AND TEST}

Test boards were fabricated to characterize transmission line impedance and confirm part performance. An 8 layer prototype circuit board was then designed, and fabricated from $370 \mathrm{H}$ material. The populated board is shown in Fig. 5.

S-parameter measurements were taken for the transmit path using a $50 \mathrm{~dB}$ high power attenuator to absorb the power (not accounted for in the result). The magnitude and phase of S21 versus input power at $435 \mathrm{MHz}$ is shown in Fig. 6. The magnitude of S21 versus frequency for three power levels is shown in Fig. 7. The results show a bandwidth of approximately $150 \mathrm{MHz}$. However, the center frequency is below the desired
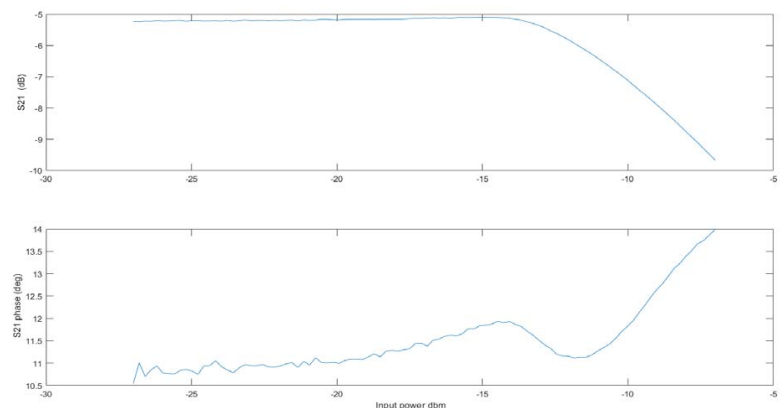

Fig. 6. Protoboard transmit path S21 magnitude and phase versus input power at $435 \mathrm{MHz}$ (add $50 \mathrm{~dB})$.

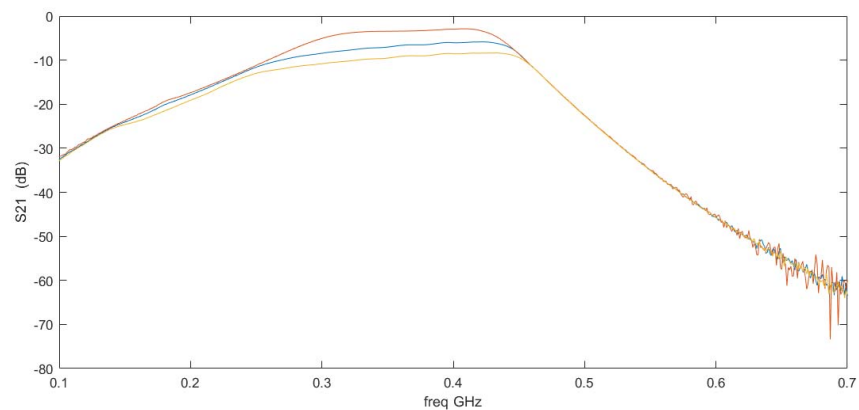

Fig. 7. Protoboard transmit path S21 magnitude versus frequency for three power levels (add $50 \mathrm{~dB}$ ).

$435 \mathrm{MHz}$ that EcoSAR used. Additional, tuning in the transmit chain is expected to account for this offset.

S-parameters were also measured for the receive path. The magnitude of S21 and S11 versus frequency is shown in Fig. 8. Excessive ripple in the upper half of the band dictates further investigation.

\section{PARTNERSHIPS}

Early in the effort we identified that off-the-shelf radio frequency (RF) power amplifiers were one of the limiting components. To provide the best capability two amplifier options were developed. As mentioned a circuit using a commercial part, was tuned for fast switching time and provided

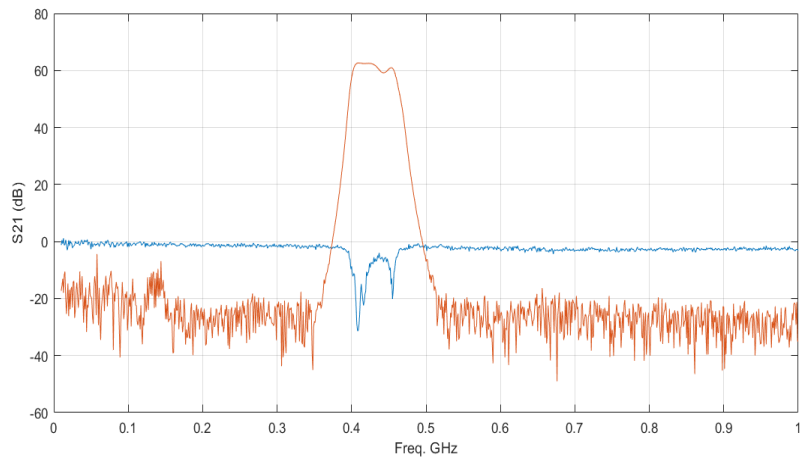

Fig. 8. Protoboard receive path S21 and S11 magnitude versus frequency. 
good efficiency. This part was included on the board as baseline.

One higher performance option has evolved from partnership with the Advanced Radar Research Center (ARRC) at the University of Oklahoma (OU). As shown in Fig. 9, OU designed an amplifier using CGHV40030 Gallium Nitride $(\mathrm{GaN})$ transistors from CREE combined with a high-speed power control circuit resulting in a design for a $10 \mathrm{~W}$ amplifier with $42 \%$ power added efficiency (PAE) and sub microsecond switching times. The prototype amplifier was fabricated on Rogers 4350B using the equipment in ARRC's Radar Innovation Laboratory.

At $10 \mathrm{~W}$ output power, the achieved gain was $43.15 \mathrm{~dB}$. The measured gain, power output, and power added efficiency as a function of input power are shown in Fig. 10.

The new SSPA will be evaluated by the ARRC with the prototype transceiver board using the built in connectors that

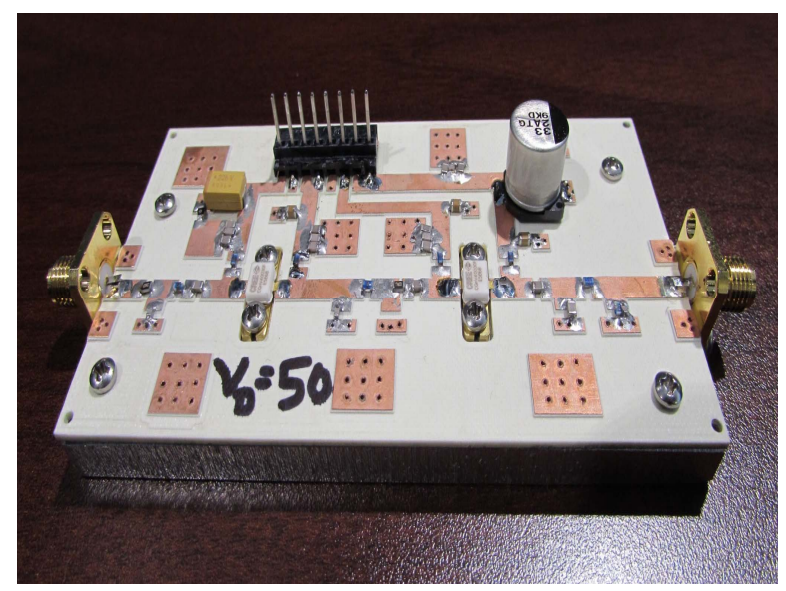

Fig. 9. OU GAN high-power high-speed amplifier prototype.

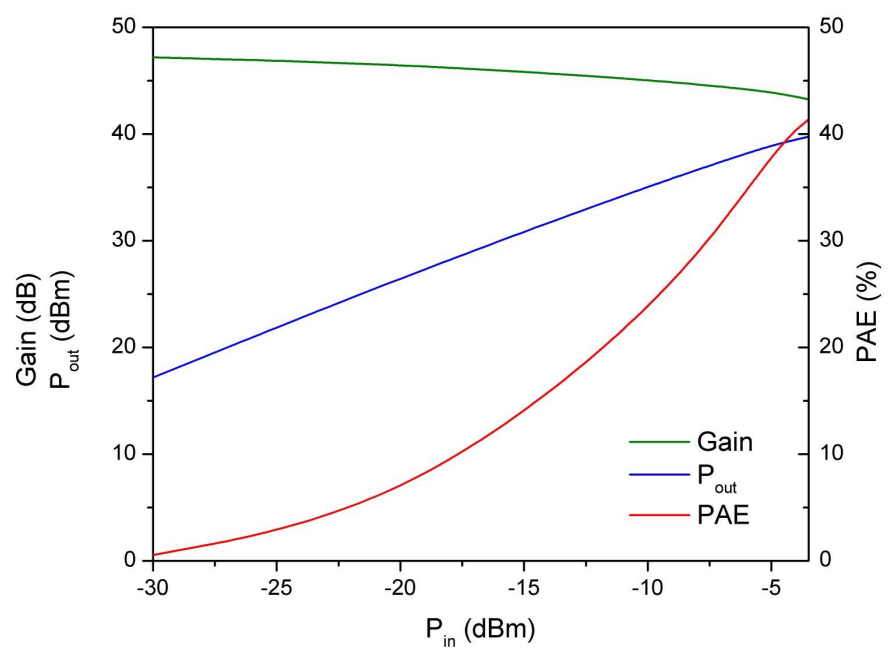

Fig. 10. Measured power amplifier gain, output power, and power added efficiency. bypass the integrated SSPA. Incorporation of the new SSPA will be considered during follow-on design cycles of the transceiver module.

\section{CONCLUSION}

We developed a miniaturized P-band prototype transceiver for Earth and planetary science P-band SAR remote sensing instruments. This prototype significantly reduces size, weight, and power compared to its airborne predecessor and has a clear path to space flight. With the noted adjustments, this unit will advance the NASA GSFC's capability to deploy a spaceborne SAR instrument by maturing the design and raising the technology readiness level.

\section{ACKNOWLEDGMENTS}

Special thanks to the following two persons: Rafal Piersiak,,a former intern, who performed many hours of detailed engineering support to the project, and Mason Bressler, from RFMD, for his assistance in tuning the SSPA application circuit for the high speed muting capability.

\section{REFERENCES}

[1] Rafael Rincon, Lynn Carter, and Daniel Lu. "Next generation P-band planetary synthetic aperture radar". IEEE International Geoscience and Remote Sensing Symposium (IGARSS); Fort Worth, Texas 2017. DOI: 10.1109/IGARSS.2017.8127838

[2] Lynn M. Carter1 , Rafael F. Rincon1, and Markus Novak2 "A REDUCED POWER DIGITAL ELECTRONICS SYSTEM FOR A DIGITAL BEAMFORMING SPACE EXPLORATION SYNTHETIC APERTURE RADAR." 3rd International Workshop on Instrumentation for Planetary Missions; Pasadena, California; Oct 2016.

[3] R. Rincon, D. Lu, M. Perrine, C. du Toit, L. Carter, "Beamforming Pband Synthetic Aperture radar for planetary applications". IEEE Radar 2018; Oklahoma City, OK; April 2018.

[4] M. Perrine, R. Rincon, Fatoyinbo T., R. Zimmerman, N. Spartana, F. Robinson, P. James, S. Seufert, M. Triesky, K. Beltran, P. Fon. "Development of the RF electronis unit for NASA's Ecological Sythetic Aperture Radar", Proc. IEEE Int. Symp on Phased Array Systems and Technology Conference, October 2013, Waltham, MA, USA.

[5] Fatoyinbo T., R. Rincon, G. Sun, K. J. Ranson, "EcoSAR: a P-band Digital Beamforming Polarimetric Interferemetric SAR instrument to measure ecosystem structure and biomass", Proc. IEEE Int. Geosci. Rem. Sens. Symp., July 25-29, 2011, Vancouver, Canada.

[6] Rincon, R. F. T Fatoyinbo, K J Ranson, G Sun, M Deshpande, R D Hale, A Bhat, M Perrine, C F Du Toit, Q Bonds, V Marrero, and P James. "Development of the EcoSAR P-band synthetic aperture radar", Proc. IEEE Int. Geosci. Rem. Sens. Symp., July 22-27, 2012, Munich, Germany.

[7] Rincon, R. F.; Vega, M. A.; Buenfil, M.; Geist, A.; Hilliard, L.; Racette, P.; 2011A, "NASA's LBand Digital Beamforming Synthetic Aperture Radar", Geoscience and Remote Sensing, IEEE Transactions on, vol. 49, no. 10, pp. 3622-3628, Oct. 2011 doi: 10.1109/TGRS.2011.2157971.

[8] Rincon, R. F.,T Fatoyinbo, J Ranson, G Sun, M Perrine, Q Bonds, S Valett, and S Seufert (2012). "Digital Beamforming Synthetic Aperture Radar (DBSAR) polarimetric operation during the Eco3D flight campaign", Proc. IEEE Int. Geosci. Rem. Sens. Symp., July 22-27, 2012, Munich, Germany.

[9] Rincon, R, M. Vega, M. Buenfil, A. Geist, L. Hilliard, and P. Racette, "DBSAR's First Multimode Flight Campaign", 2010 European Radar Conference, EUSAR, 2010. 